\title{
Treatment of Caustic Ingestion Associated Esophageal Stricture with Budesonide
}

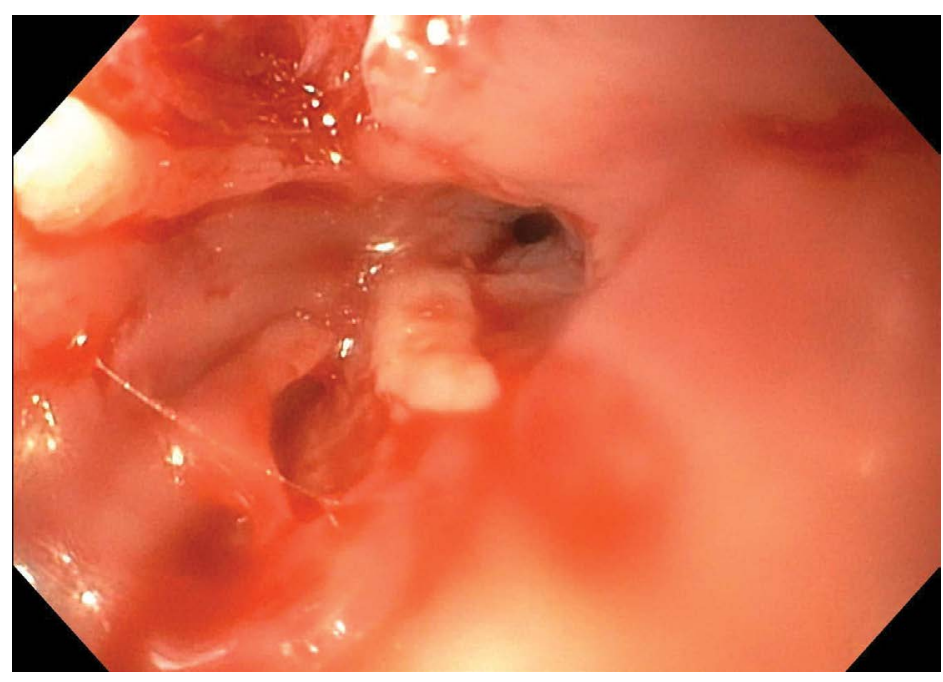

Figure 1: EGD after caustic ingestion.

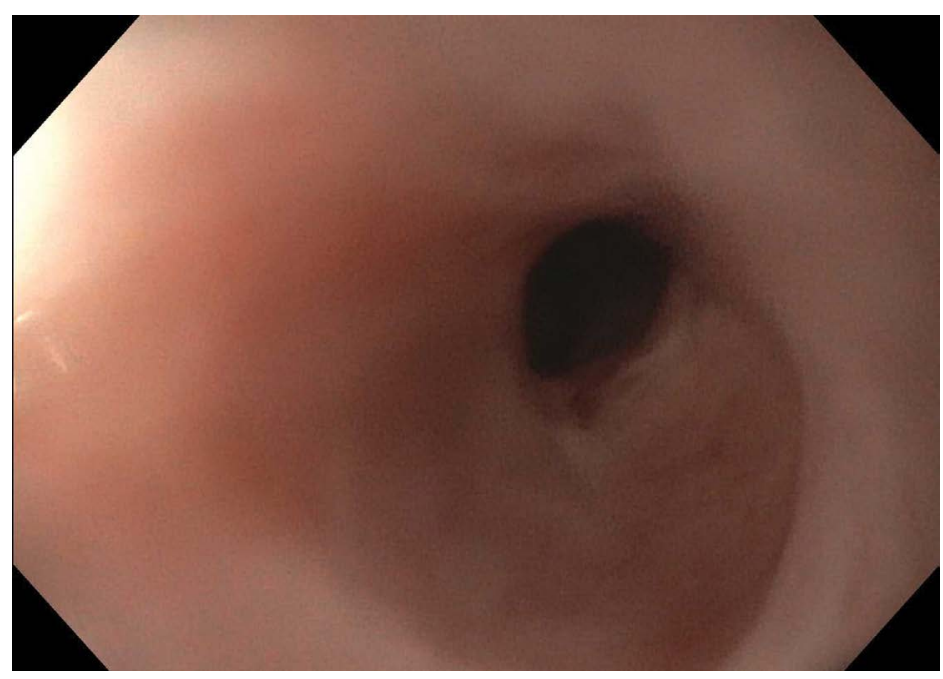

Figure 2: EGD after topical budesonide.

\section{Information}

Marisa L Gallant ${ }^{1 *}$, Sabina A Mir ${ }^{2}$ and Steven N Lichtman ${ }^{2}$

${ }^{1}$ Department of Pediatrics, Division of General Pediatrics and Adolescent Medicine, University of North Carolina, USA

${ }^{2}$ Department of Pediatrics, Division of Pediatric Gastroenterology, University of North Carolina School of Medicine, USA

*Correspondence: Marisa L Gallant, Department of Pediatrics, Division of General Pediatrics and Adolescent Medicine, University of North Carolina, 260 MacNider Building, CB\#7220, USA, Tel: (919)9661505, E-mail: mgallant@unch.unc.edu
Citation: Gallant ML, Mir SA, Lichtman SN (2016) Treatment of Caustic Ingestion Associated Esophageal Stricture with Budesonide. Clin Med Img Lib 2:046

\section{Published: June 13, 2016}

Copyright: () 2016 Gallant ML, et al. This is an open-access content distributed under the terms of the Creative Commons Attribution License, which permits unrestricted use, distribution, and reproduction in any medium, provided the original author and source are credited.

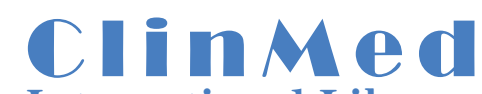

International Library 


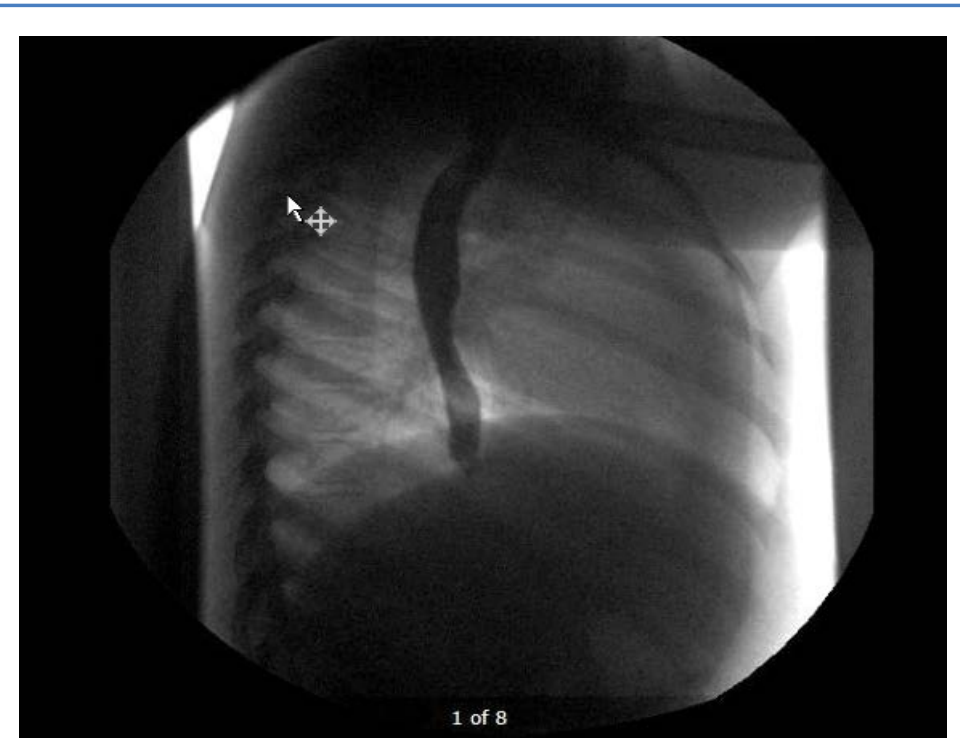

Figure 3: UGI after topical budesonide.

\begin{abstract}
We present the images from the upper endoscopy of a 5-year-old patient who developed an esophageal stricture from caustic ingestion. These images are from before and after a two-week course of topical budesonide. Her remarkable improvement suggests that we need more studies to investigate topical steroid use for caustic esophageal injury.
\end{abstract}

Keywords: Caustic ingestion, Esophageal stricture, Steroids, Endoscopy

A 5-year-old patient presented with grade II esophageal injury due to an industrial strength bleach ingestion, which progressed to an esophageal stricture (Figure 1). Her initial treatment included standard of care with omeprazole and serial endoscopic dilations. Five weeks after her initial ingestion, the patient was placed on topical budesonide due to persistent dysphagia and weight loss. Two weeks later, repeat endoscopy visualized the esophageal stricture. There was marked improvement in the stricture diameter and evidence of mucosal healing (Figure 2). Clinically, her dysphagia resolved and she gained weight. Several weeks later, a repeat esophagram showed radiographic resolution of the stricture (Figure 3).

Caustic ingestions are a significant cause of morbidity and mortality in the pediatric population. Risk of esophageal stricture with Grade II injury is reported to be as high as $77 \%$ [1].

Multiple studies have examined the use of systemic and intralesional corticosteroids for prevention of esophageal stricture after caustic ingestions. Their role remains controversial [2-6].

In pediatric eosinophilic esophagitis, topical steroids are used safely to treat inflammation and to prevent stricturing [7-8]. However, there remains a paucity of literature describing the use of topical steroids for esophageal stricture after caustic ingestion.

While we cannot make a definitive statement as to the cause of this patient's remarkable recovery, this case highlights the need for studies on the role of topical steroids in treatment of caustic esophageal injury.

\title{
Author Roles
}

1. Marisa Gallant- Reviewed case, prepared draft

2. Sabina Mir- Patient management with topical budesonide and endoscopic dilatation, revised draft and gave final approval for publication

3. Steven Lichtman- Initial management of patient, revised draft and gave final approval for publication

\section{References}

1. Mortada E, Hassan H (2011) Caustic ingestion in children. Expert Review of Gastroenterology \& Hepatology 5: 637-645.

2. Bouthkir S, Fetni S, Monglagi M, Debbabi A, Barsaoui S, et al. (2004) High doses of steroids in the management of caustic esophageal burns in children. Arch Pediatr 11: 13-17.

3. Pelclova D, Navratil T (2005) Do Corticosteroids prevent oesophageal stricture after corrosive ingestion? Toxicol Review 24: $125-129$.

4. Ulman I, Mutaf O (1998) A critique of systemic steroids in the management of caustic esophageal burns in children. Eur J Pediatr Surg 8: 71-74.

5. Usta M, Erkan T, Fugen Cullu Cokugras, Nafiye Urganci, Zerrin Onal, et al. (2004) High doses of methylprednisolone in the management of caustic esophageal burns. Pediatrics 133: 1518-1524.

6. Gunarsson M (1999) Local corticosteroid treatment of caustic injuries of the esophagus. A preliminary report. Ann Otol Rhinol Laryngol 108: $1088-1090$.

7. Molina-Infante J, Lucendo AJ (2015) Update on topical steroid therapy for eosinophilic esophagitis. Groenterol Hepatol 38: $388-397$.

8. von Arnim U, Malfertheiner P (2014) Eosinophilic esophagitis treatment of eosinophilic esophagitis with drugs: corticosteroids. Dig Dis 32: 126-129. 